\title{
Karl Polanyi e a Nova Sociologia Económica: Notas sobre o conceito de (dis)embeddedness
}

Karl Polanyi and the New Economic Sociology: Notes on the Concept of

(Dis)embeddedness

Karl Polanyi et la Nouvelle Sociologie Économique: notes sur le concept de

(dis)embeddedness

Nuno Miguel Cardoso Machado

\section{(2) OpenEdition}

\section{Journals}

Edição electrónica

URL: http://journals.openedition.org/rccs/1771

DOI: $10.4000 /$ rccs. 1771

ISSN: 2182-7435

\section{Editora}

Centro de Estudos Sociais da Universidade de Coimbra

\section{Edição impressa}

Data de publição: 1 setembro 2010

Paginação: 71-94

ISSN: 0254-1106

\section{Refêrencia eletrónica}

Nuno Miguel Cardoso Machado, « Karl Polanyi e a Nova Sociologia Económica: Notas sobre o conceito de (dis)embeddedness », Revista Crítica de Ciências Sociais [Online], 90 | 2010, posto online no dia 15 outubro 2012, consultado o 10 dezembro 2020. URL : http://journals.openedition.org/rccs/ 1771 ; DOI : https://doi.org/10.4000/rccs.1771 


\title{
NUNO MIGUEL CARDOSO MACHADO
}

\section{Karl Polanyi e a Nova Sociologia Económica: Notas sobre o conceito de (dis)embeddedness}

\begin{abstract}
No contexto da Nova Sociologia Económica, Karl Polanyi é quase consensualmente considerado o "pai" do conceito de incrustação (embeddedness). Todavia, este conceito foi alvo de uma apropriação selectiva por parte da disciplina, sendo negligenciada a sua relação com o restante edifício teórico construído por Polanyi. Pode, com efeito, falar-se de uma "grande transformação" sofrida pelo conceito de incrustação: se em Polanyi ele está associado a um nível macro(económico) e é utilizado para evidenciar o carácter excepcional da economia capitalista de mercado - que se encontra desincrustada da sociedade -, na NSE, por seu turno, é normalmente associado a um nível meso (e até micro), sendo preconizado que todas as economias - incluindo a capitalista - estão incrustadas.
\end{abstract}

Palavras-chave: capitalismo; economia de mercado; incrustação; Karl Polanyi; Nova Sociologia Económica.

\section{Introdução}

No panorama das ciências sociais, Karl Polanyi é usualmente considerado o "pai" do conceito de incrustação (embeddedness). A Nova Sociologia Económica (NSE) não constitui excepção, tendo mesmo adoptado este como um dos seus conceitos centrais (cf. Krippner, 2001; Swedberg, 2006). Todavia, o conceito foi alvo de uma apropriação selectiva por parte da disciplina, sendo negligenciada a sua relação com o restante edifício teórico construído por Polanyi. Pode, com efeito, falar-se de uma "grande transformação" (Beckert, 2007) sofrida pelo conceito de incrustação: se em Polanyi ele se encontra associado a um nível macro(económico) e é utilizado para evidenciar o carácter excepcional da economia capitalista de mercado - que se encontra desincrustada da sociedade -, na NSE, por seu turno, é normalmente associado a um nível meso (e até micro), sendo preconizado que todas as economias - incluindo a capitalista - estão incrustadas, ou seja, as acções económicas dos indivíduos estão sempre inseridas em redes de relações sociais. 
Para Polanyi, a incrustação ${ }^{1}$ da economia implica que esta esteja submersa nas relações sociais, ou seja, que não constitua uma esfera desvinculada e autónoma em relação à sociedade. Deve, contudo, salientar-se que o autor não pretendeu introduzir deliberadamente um novo conceito, não revelando aliás uma grande preocupação em defini-lo explicitamente. Talvez por isso mesmo, o conceito de (des)incrustação tem sido alvo de diversas interpretações contraditórias. No entanto, a melhor maneira de entender o verdadeiro significado e implicações deste conceito é apreendê-lo em estreita ligação com a totalidade do edifício conceptual e teórico construído por Polanyi, i.e., captando o papel, a função, a relação e o lugar que ocupa no seio do pensamento polanyiano. Por outro lado, tentar compreender este conceito única e exclusivamente a partir de afirmações isoladas do autor - nomeadamente a partir dos casos em que o conceito aparece explicitamente em $A$ grande transformação - revelar-se-á por certo um empreendimento infrutífero e mistificador, ao invés de esclarecedor (como veremos ser o caso no contexto da Nova Sociologia Económica).

Já demonstrei noutro lugar o carácter extremamente singular da moderna economia capitalista de mercado na óptica de Polanyi (cf. Machado, 2009). Procurarei então sintetizar alguns dos seus principais conceitos. Para se compreender em toda a sua plenitude a obra e o pensamento de Polanyi, deve começar-se por analisar a distinção que o autor faz entre economia no sentido substantivo e economia no sentido formal. A abordagem formalista parte de uma escassez ontológica dos meios para satisfazer as necessidades humanas e tem como objecto da sua análise o indivíduo ("racional") isolado que procura maximizar os seus ganhos, ou seja, cinge-se aos predicados do homo economicus. Segundo Polanyi, o esquema formalista - assente no modelo neoclássico da teoria económica - apenas é aplicável ao estudo das modernas economias capitalistas, onde os mercados formadores de preços desempenham um papel fulcral. ${ }^{2}$ Por seu turno, a abordagem

\footnotetext{
${ }^{1}$ Thurnwald, um dos autores que mais influenciou Polanyi no campo da antropologia económica, já havia utilizado este conceito nos seus estudos. Assim, terá sido nele que Polanyi se inspirou para a adopção do conceito de incrustação (cf. Beckert, 2007: 7). Block (cf. 2000: 7), por seu turno, sugere que Polanyi se inspirou num termo utilizado na mineração: ao estudar a história económica inglesa na preparação para a elaboração de $A$ grande transformação, ele terá lido extensamente sobre a história das tecnologias da indústria mineira inglesa que tinham como tarefa extrair o carvão "incrustado" (embedded) nas paredes rochosas das minas.

${ }^{2} \mathrm{Um}$ referee questiona oportunamente se, segundo Polanyi, a teoria formalista é inteiramente aplicável ao estudo da economia de mercado capitalista. É certo que Polanyi afirma que "até no que se refere ao sistema de mercado em si mesmo, o mercado enquanto único quadro de referência está cada vez mais ultrapassado" (Polanyi, 1968a: 174), mas também refere que "uma vez estando o ser humano circunscrito ao 'indivíduo no mercado', as proposições [formalistas] são fáceis de substanciar" (Polanyi, 1977c: 29). A economia capitalista envolve os indivíduos em escolhas induzidas por
} 
substantivista versa sobre as formas institucionais que o processo de satisfação das necessidades humanas reveste nas diferentes sociedades, do passado e do presente, procurando estudar o lugar ocupado pela economia na sociedade. A sua preocupação é a suficiência, ao invés da eficiência.

Assim, de acordo com o autor, deve reconhecer-se a relevância da definição substantiva, que encara a economia enquanto processo instituído de interacção entre o homem e o seu ambiente natural e social, o qual resulta numa contínua oferta de meios materiais para satisfazer as suas necessidades - esta sim com carácter universal - e que constitui a base para o método preconizado por Polanyi: a análise institucional. Ora, a economia pode estar instituída de diferentes formas nas mais variadas sociedades, sendo que Polanyi identifica três padrões fundamentais designados por formas de integração - reciprocidade, redistribuição e troca (mercantil) -, mediante a combinação das quais a economia adquire unidade e estabilidade, i.e., a interdependência e a recorrência das suas partes. ${ }^{3}$

De acordo com a classificação do autor, nas sociedades primitivas ou tribais opera a reciprocidade e, também, em parte, a redistribuição. Por sua vez, as sociedades arcaicas são predominantemente redistributivas, embora possa haver espaço para alguma troca. Todavia, o facto a reter é que apenas nas sociedades modernas o sistema de mercados auto-regulados se assume como forma de integração dominante. Assim, podemos concluir que a tentativa polanyiana de formalizar uma ciência económica comparada - a qual seja genericamente relevante - e, neste sentido, a importância do conceito de incrustação, derivam precisamente da necessidade sentida pelo autor

uma insuficiência de meios, pelo que pode ser analisada com a aplicação dos métodos baseados no significado formal da economia. Enquanto vigorar este sistema económico, os significados formal e substantivo coincidem na prática (Polanyi, 1968a: 141; Polanyi, 1977a: 10-11), pois os arranjos institucionais que garantem a subsistência humana correspondem àqueles assumidos pelo formalismo. Esta é uma discussão que extravasa o âmbito deste artigo, mas podemos assumir (pacificamente) que Polanyi apenas concede uma capacidade explicativa, maior ou menor, ao esquema formalista quando este é aplicado à moderna economia capitalista.

3 Cf. Machado (2009: 54-68; 79-89) para uma análise das formas de integração propostas por Polanyi, assim como da sua aplicação empírica na obra Dahomey and the Slave Trade. De um modo sucinto, a reciprocidade denota movimentos entre pontos correlativos de grupos simétricos; por conseguinte, pressupõe como pano de fundo institucional (background) a existência de simetria. Trata-se de um sistema de dádivas e contra-dádivas, um tomar e dar sucessivos (por exemplo, o circuito Kula de Malinowski). A redistribuição designa movimentos apropriativos em direcção a um centro e, também, em sentido inverso (do centro para "fora"); em termos institucionais, está dependente da presença de algum grau de centralidade (centricity) no grupo (e.g., impérios antigos - egípcio, romano, etc.; Daomé). A troca refere-se aos movimentos "vice-versa" que ocorrem entre os "agentes" sob um sistema de mercado; portanto, de modo a produzir integração, requer um sistema de mercados formadores de preços. A troca mercantil (exchange) consiste pois num movimento bidireccionado (two-way) de bens entre pessoas, orientado para o ganho que resulta para os participantes. 
de salientar enfaticamente as diferenças entre os vários sistemas sociais e económicos, nomeadamente entre o capitalismo e todas as sociedades que o precederam. O mote que norteia todo o pensamento de Karl Polanyi é o intuito de realçar a absoluta excepcionalidade da economia de mercado ${ }^{4}$ na história da humanidade. A condição de incrustação/desincrustação deve, acima de tudo, ser entendida no âmbito dessa distinção.

\section{Karl Polanyi: a desincrustação da economia capitalista}

De facto, como é queixa comum em vários autores, o conceito de incrustação só é utilizado em $A$ grande transformação em duas ocasiões. Todavia, o leitor munido da perspectiva adequada, ou seja, após a análise e estudo do pensamento polanyiano como um todo, conseguirá captar aí o sentido do conceito em toda a sua plenitude:

O padrão de mercado, relacionando-se com um motivo peculiar próprio, o motivo da barganha ou da permuta, é capaz de criar uma instituição específica, a saber, o mercado. Em última instância, é por isto que o controlo do sistema económico pelo mercado é consequência fundamental para toda a organização da sociedade: significa, nada menos, dirigir a sociedade como se fosse um acessório do mercado. Em vez de a economia estar incrustada nas relações sociais, são as relações sociais que estão incrustadas no sistema económico. A importância vital do factor económico para a existência da sociedade antecede qualquer outro resultado. Desta vez, o sistema económico é organizado em instituições separadas, baseado em motivos específicos e concedendo um status especial. A sociedade tem que ser modelada de maneira tal a permitir que o sistema funcione de acordo com as suas próprias leis. Este é o significado da afirmação familiar de que uma economia de mercado só pode funcionar numa sociedade de mercado. (Polanyi, 2000: 77, itálico nosso)

Nos amplos sistemas antigos de redistribuição, os actos de permuta e os mercados locais eram uma constante, porém apenas em carácter subordinado. O mesmo se aplica onde a reciprocidade é a regra: aqui, os actos de permuta estão geralmente incrustados em relações de longo alcance que implicam aceitação e confiança, uma situação que tende a obliterar o carácter bilateral da transacção. (Polanyi, 2000: 81-82, itálico nosso)

Estas citações traduzem perfeitamente o facto elementar de que Polanyi contrasta abertamente, ao longo de toda a sua obra, a sociedade capitalista com as comunidades do passado, onde a economia, revestindo outros

\footnotetext{
${ }^{4}$ Podemos clarificar melhor o conceito de capitalismo: em Polanyi, o capitalismo é definido como um sistema interligado de mercados formadores de preços (price making markets), ou seja, como uma economia de mercado (regulada pelo mecanismo da oferta e da procura).
} 
padrões institucionais, não constituía uma esfera separada - na maior parte das vezes sequer identificável e diferenciável - da sociedade, estando plenamente submersa nas relações sociais. Pelo contrário, no capitalismo a economia desincrustou-se (i.e., desvinculou-se, autonomizou-se, se quisermos), ficando o destino da sociedade entregue a um mecanismo cego - o mercado auto-regulado - que a controla e subjuga. Assim, na prática, a incrustação da economia traduz-se na ausência de um sistema de mercados formadores de preços.

Para além disso, e mais importante, apenas uma análise superficial se deterá na procura explícita e literal do conceito para poder apreender o seu significado. Como se compreenderá, decerto que é bastante redutor cingir a investigação à procura ou à contagem do número de vezes em que aparece o termo "(des)incrustação". Deve-se notar que, ao longo de toda a sua obra, Polanyi expressa ideias análogas sem recorrer contudo forçosamente a esse mesmo termo. Senão, vejam-se dois exemplos bastante ilustrativos, também em $A$ grande transformação, e que são normalmente esquecidos:

A descoberta mais importante nas recentes pesquisas históricas e antropológicas é que a economia do homem, em regra, está submersa nas suas relações sociais. Ele não age para salvaguardar o seu interesse individual na posse de bens materiais, ele age para salvaguardar a sua situação social, as suas exigências sociais, o seu património social. Ele valoriza os bens materiais [apenas] na medida em que servem os seus propósitos [sociais]. Nem o processo de produção, nem o de distribuição está ligado a interesses económicos específicos relativos à posse de bens. Cada passo deste processo está atrelado a um certo número de interesses sociais, e são estes que asseguram a necessidade daquele passo. É natural que esses interesses sejam muito diferentes numa pequena comunidade de caçadores ou pescadores e numa ampla sociedade despótica, mas tanto numa como noutra o sistema económico será dirigido por motivações não económicas. (Polanyi, 2000: 65, itálico nosso)

Um mercado auto-regulável exige, no minimo, a separação institucional da sociedade em esferas económica e política. Do ponto de vista da sociedade como um todo, uma tal dicotomia é, com efeito, apenas um reforço da existência de um mercado auto-regulável. Pode-se argumentar que a separação dessas duas esferas ocorre em todos os tipos de sociedade, em todos os tempos. Uma tal inferência, porém, seria baseada numa falácia. É verdade que nenhuma sociedade pode existir sem algum tipo de sistema que assegure a ordem na produção e distribuição de bens. Entretanto, isto não implica a existência de instituições económicas separadas. Normalmente, a ordem económica é apenas uma função da social, na qual ela está inserida. Como já demonstrámos, não havia um sistema económico separado na sociedade, seja sob 
condições tribais, feudais ou mercantis [mercantilistas]. A sociedade do século XIX revelou-se, de facto, um ponto de partida singular, no qual a actividade económica foi isolada e imputada a uma motivação económica distinta. (Polanyi, 2000: 92-93, itálico nosso)

Note-se que a intervenção ou regulação estatal não significa que a economia esteja incrustada. Podemos distinguir, em Polanyi, dois tipos de regulamentação que não contradizem a existência empírica de uma economia desincrustada, estando aliás intimamente associadas à implementação histórica da mesma: a) instauração dos pressupostos da economia de mercado (enclosures, instauração de um mercado de trabalho "livre", etc.); b) medidas de protecção face à desincrustação, essencialmente para abrandar o ritmo de mudança imposto pela transformação numa economia de mercado (legislação laboral, Speenhamland, etc.).

A regulamentação estatal apenas enquadra o funcionamento do mercado (auto-regulado), não podendo ditar esse funcionamento (aliás, isso seria um contra-senso). De acordo com Polanyi, há um conjunto de pressupostos em relação ao Estado e à sua política, devendo ser evitada qualquer medida ou política que possa influenciar a acção dos mercados. Nem o preço, nem a oferta, nem a procura devem ser fixados ou regulados; só terão validade as políticas e as medidas que ajudem a assegurar a auto-regulação do mercado, criando as condições para fazer do mercado o único poder organizador na esfera económica (Polanyi, 2000: 90-91; Stanfield, 1986: 111). Para Polanyi, a existência do Estado, por si só, do Estado "liberal" (democrático) não é sinónimo de incrustação, tal como as medidas de protecção social não são sinónimo de (re)incrustação. A separação entre economia e política é, pelo contrário, a prova da desincrustação.

Se compreendermos a importância do conceito de (des)incrustação como estando intimamente associada à análise comparativa que Polanyi faz entre a economia de mercado e as economias do passado, então a sua centralidade no pensamento Polanyiano é por demais evidente. Se, por outro lado, estivermos mais preocupados em contar o número de vezes em que a expressão "desincrustação" aparece efectivamente nas suas obras, então concluiremos - falaciosamente - que o mesmo era pouco relevante para Polanyi e o leitmotiv da investigação empreendida pelo autor passar-nos-á ao lado. Mais, provavelmente daremos pouca importância ao significado original e tenderemos a descartá-lo como um mero equívoco, apropriando selectivamente o que afinal era mais importante para nós: o termo "(des)incrustação", obviamente com um outro significado. Julgo que foi isto que sucedeu na NSE. Mas voltarei a este assunto mais adiante. 
Não obstante, realce-se que o termo “(des)incrustação" não é utilizado assim tão poucas vezes por Polanyi. ${ }^{5}$ Todavia, a maioria dos autores limita-se a referir as duas vezes em que aparece na sua magnum opus, esquecendo-se usualmente de ler a restante obra de Polanyi (cf., por exemplo, Barber, 1995; Ghezzi \& Mingione, 2007; Granovetter, 1985. Swedberg [1997, 2004] não inclui uma única referência a Polanyi na sua bibliografia).

É contudo num artigo intitulado "Aristotle Discovers the Economy" (cf. Polanyi, 1957), quase sempre esquecido na literatura, que Polanyi utiliza porventura o conceito de embeddedness de um modo mais claro e sistemático. Permita-se-nos uma citação longa, mas que pensamos ser bastante ilustrativa - talvez a mais elucidativa - no que respeita ao conceito de des(incrustação):

Preconizamos que o instrumento conceptual para apreender esta transição de um anonimato [da economia] para uma existência separada é dado pela distinção entre a condição de incrustação e desincrustação da economia relativamente à sociedade. A economia desincrustada do século XIX estava separada do resto da sociedade, mais especificamente do sistema político e governativo. Numa economia de mercado a produção e a distribuição dos bens materiais é em princípio conduzida através de um sistema auto-regulado de mercados formadores de preços. É governada por leis próprias, as chamadas leis da oferta e da procura, e motivada pelo receio da fome e pelo desejo de ganho. Não são os laços de sangue, a compulsão legal, a obrigação religiosa, a fidelidade ou a magia que criam as situações sociológicas que levam os indivíduos a participar na vida económica, mas antes instituições especificamente económicas tais como a empresa privada e o sistema de trabalho assalariado.

[...] Sob um sistema de mercado a subsistência do homem é assegurada através de instituições, que são activadas por motivos económicos, e governada por leis que são especificamente económicas. O vasto e abrangente mecanismo da economia pode ser concebido como funcionando sem a intervenção consciente da autoridade bumana, do estado ou do governo.

Esta é, portanto, a versão do século XIX de uma esfera económica independente na sociedade. É distinta no que toca às motivações, pois recebe o seu impulso da necessidade urgente de um ganho monetário. Está separada institucionalmente do centro político e governamental. Alcança uma autonomia que a investe com leis próprias. Nela [na economia do século XIX] encontramos o caso extremo de uma economia desincrustada que teve origem no uso alargado do dinheiro enquanto meio de troca. (Polanyi, 1957: 67-68, itálico nosso)

${ }^{5}$ Cf. Polanyi (1966: 60, 81; 1968a: 141, 148; 1968b: 70; 1977a: 9; 1977b: 53; Polanyi et al., 1968: 118-119). 
Parece óbvio que, para o autor, a economia de mercado estava efectivamente desincrustada. ${ }^{6}$ Podemos afirmar que "a economia de mercado criou um novo tipo de sociedade. $\mathrm{O}$ sistema produtivo ou económico passou a estar confiado a um aparelho automatizado (self-acting device). Um mecanismo institucional controla os seres humanos nas suas actividades quotidianas assim como os recursos naturais" (Polanyi, 1968b: 62). E Polanyi contrasta ainda mais a sociedade capitalista com as sociedades primitivas e arcaicas, acrescentando:

Enquanto estas formas de integração [i.e., a reciprocidade e a redistribuição] prevalecerem, não necessita de surgir nenhum conceito de economia. Os elementos da economia estão aqui incrustados em instituições não-económicas, estando o próprio processo económico incrustado através do parentesco, casamento, grupos etários, sociedades secretas, associações totémicas, e solenidades públicas. O termo 'vida económica' não teria neste quadro qualquer significado óbvio. [...] [Também] não existia, em regra, nenhum termo para designar o conceito de economia. [...] Este conceito estava [simplesmente] ausente. [...] A principal razão para a ausência de qualquer conceito de economia é a dificuldade em identificar o [próprio] processo económico sob condições em que o mesmo está incrustado em instituições não-económicas. (Polanyi, 1957: 70-71)

Neste sentido, nas sociedades do passado, a economia não só estava incrustada na sociedade como, na maior parte dos casos, dela estava ausente a própria noção, conceito ou consciência de uma esfera económica claramente identificável ou reconhecível como tal pelos membros dessas sociedades.

\footnotetext{
${ }^{6}$ Um referee questiona a possível representatividade desta (longa) citação no seio da obra de Polanyi. Escutemos Polanyi: com o capitalismo, "emergiu uma 'esfera económica' que está perfeitamente delimitada das outras instituições da sociedade. Uma vez que nenhum agregado humano pode sobreviver sem um aparelho produtivo funcional, a sua corporização (embodiment) numa esfera distinta e separada produziu o efeito de tornar o resto da sociedade dependente desta esfera [... ] Como resultado, o mecanismo de mercado tornou-se um factor determinante para a vida do corpo social. Não admira que o agregado humano emergente corresponda a uma sociedade 'económica' num grau nunca antes visto" (Polanyi, 1968b: 63). Segundo Polanyi, a identificação dos fenómenos económicos com os fenómenos de mercado tornou-se quase um requisito prático com a emergência da nova sociedade e do seu modo de vida nascido dos primórdios da Revolução Industrial (Polanyi, 1977a: 9). Neste sentido, "o que designámos por falácia economicista foi [é] um erro essencialmente do ponto de vista teórico. Isto porque, para todos os efeitos práticos, a economia consiste agora de facto em mercados e o mercado envolve de facto a sociedade" (Polanyi, 1977a: 9). Cf. ainda, por exemplo, Polanyi (1968b: 70; 1977a: 9; 1977b: 53). Polanyi-Levitt (cf. 2003: 2-3) realça igualmente a centralidade da desincrustação da economia capitalista para Polanyi.
} 


\title{
3. A Nova Sociologia Económica: "todas as economias estão incrustadas"
}

\subsection{A NSE e o conceito de incrustação \\ Como refere Swedberg,}

Sociologia económica é um termo que raramente se ouvia há uma década atrás, mas que se tornou novamente bastante popular. Hoje em dia os departamentos de sociologia são classificados de acordo com a sua proeminência neste campo, e todos os anos surge um número considerável de artigos e livros que se identificam com essa designação. $(2006: 2)^{7}$

Por seu turno, Graça salienta acertadamente que "no panorama da teoria social das últimas décadas, o surgimento da chamada 'nova sociologia económica' (NSE), associado sobretudo aos nomes de Mark Granovetter e de Richard Swedberg, ${ }^{8}$ é um facto de primordial relevância e significado" (2005: 111).

Um dos desenvolvimentos mais importantes nas ciências sociais durante as últimas décadas foi a tentativa de preencher o vazio criado pelo falhanço da ciência económica mainstream no que toca à investigação das instituições económicas. É precisamente neste contexto que temos de entender o surgimento da Nova Sociologia Económica (Swedberg, 1997: 161). Todavia, como observa mais uma vez Graça:

\begin{abstract}
A NSE atreveu-se a contestar, embora de forma limitada, alguns dos pressupostos e dos métodos da economia académica. Mas, ao mesmo tempo, apressou-se a balizar o âmbito do seu próprio empreendimento de contestação, tendendo uma e outra vez a regressar à tradicional alegação auto-legitimadora da existência de diversos pontos de vista ou ângulos de análise, o seu próprio sendo apenas mais um outro, a justapor, mais do que a contrapor, ao da economics. . (2005: 111, itálico nosso)
\end{abstract}

\footnotetext{
7 À excepção de Polanyi (2000) - tradução portuguesa de $A$ grande transformação - todas as traduções presentes no artigo são da minha responsabilidade.

${ }^{8}$ Entre as principais figuras da NSE, para além de Swedberg e Granovetter, encontram-se Patrik Aspers, Jens Beckert, Ronald Burt, Michel Callon, Bruce Carruthers, Neil Fligstein, Philippe Steiner ou Viviana Zelizer (cf. Swedberg, 2006: 20-21). Note-se que a NSE tem sido um fenómeno, no essencial, cingido à América do Norte, embora possua um pequeno número de investigadores em vários países europeus (Swedberg, 1997: 164).

${ }^{9}$ Beckert expressa uma opinião similar: "a sociologia económica possui um denominador comum na sua crítica [...] da noção do homo economicus que age num mundo com informação perfeita, tomando decisões independentes, com plena competitividade e preferências fixas. [...] [Não obstante,] a nova sociologia económica não consegue colocar ênfase suficiente na proposta de uma alternativa à teoria da acção racional" (2003: 769 e 770, itálico nosso).
} 
Esta disciplina tem as suas raízes em alguns trabalhos do início da década de 1980, mas se tivermos de escolher um ano para assinalar o seu verdadeiro "nascimento", esse será o de 1985, altura em que foi publicado aquele que se viria a tornar no artigo mais popular da sociologia económica contemporânea por parte de Granovetter (cf. ibidem, 1985; Swedberg, 1997: 161-162). Deve-se contudo realçar que, ao contrário da economia (economics) moderna, a sociologia económica não possui ainda um núcleo básico de ideias e conceitos, moldados, conjugados e trabalhados ao longo de um período de tempo alargado. Ao invés, a sociologia económica, à semelhança do que se passa na sociologia, consiste num conjunto de perspectivas "rivais", umas mais coerentes do que outras (Swedberg, 2006: 3).

Não obstante, destacam-se alguns conceitos centrais que já adquiriram uma certa proeminência. Entre eles encontramos o conceito de incrustação (embeddedness) e, associado a ele, o de redes (sociais). Swedberg afirma mesmo que "o conceito mais famoso na sociologia económica contemporânea é de longe o de incrustação” (2006: 3). E Krippner acrescenta que "a noção de incrustação ocupa uma posição privilegiada - e largamente incontestada - como o princípio organizador da sociologia económica [...] [Com efeito,] o termo ganhou uma enorme aceitação enquanto representante do núcleo dos temas unificadores nesse subcampo da sociologia" (Krippner, 2001: 775). A centralidade da incrustação para a 'nova sociologia económica' (desde meados dos anos 80 a esta parte) é indubitável (Swedberg, 2006: 3). ${ }^{10}$

Swedberg denota que Granovetter (1985) introduziu um conceito de incrustação diferente e, segundo ele, analiticamente mais útil do que o proposto por Polanyi. Em primeiro lugar, desafiou a dimensão política das ideias de Polanyi ao argumentar que as economias pré-capitalistas estavam tão incrustadas como a economia capitalista, no sentido em que ambas são sociais, estão incrustadas na estrutura social. Em segundo lugar, imprimiu ao conceito de incrustação uma maior precisão analítica ao insistir que todas as acções económicas estão incrustadas em redes de relações sociais. ${ }^{11}$ Assim, não existe tal coisa como uma incrustação da economia em geral; todas as acções económicas assumem uma expressão interpessoal; e graças à teoria das redes, esta expressão pode agora ser definida com precisão (Swedbeg, 2006: 4).

\footnotetext{
${ }^{10}$ O conceito de incrustação também tem sido utilizado noutras disciplinas. Para além da antropologia económica, nomeadamente mediante a influência de Polanyi sobre a corrente substantivista, saliente-se ainda a geografia económica (cf. Hess, 2004), a arqueologia (cf. Cumberpatch, 2001) e a história (cf. Knowles, 2000; Knowles e Owen, 2008).

${ }^{11}$ Swedberg salienta ainda em outro trabalho que, enquanto Polanyi introduziu a noção de incrustação para salientar que a economia era uma parte orgânica da sociedade nos tempos pré-capitalistas, $o$ objectivo de Granovetter com este conceito é quase o inverso: demonstrar que as acções económicas são verdadeiramente acções sociais no seio da sociedade capitalista (Swedberg, 1997: 165).
} 
Deste modo, aquilo que torna o conceito de incrustação bastante útil, de acordo com a opinião de muitos sociólogos económicos, são as suas ligações à teoria das redes. Este tipo de método, que se tornou bastante popular na actual (nova) sociologia económica, providencia o analista com uma medida (metric) para analisar as interacções sociais, incluindo as económicas. Sendo um método que assenta numa dimensão (representação) visual bastante pronunciada, a teoria das redes proporciona ao investigador um instrumento que pode rapidamente traduzir e interpretar relações sociais complexas (Swedberg, 2006: 4-5).

Podemos concluir que o advento da NSE surgiu associado a um conjunto de ideias-chave: todas as acções económicas estão "incrustadas"; os mercados podem ser conceptualizados como "estruturas sociais"; e as acções económicas possuem não apenas uma componente racional, como também uma componente sociocultural (Swedberg, 2004: 317).

Termino com uma passagem interessante de Swedberg:

A sociologia económica, tal como existe hoje, pode ser descrita como um subcampo da sociologia bem estabelecido e com uma identidade própria bem definida [...]. Desde os anos 80 tem-se sentido claramente a importância de a sociologia económica adquirir o seu próprio perfil, capaz de a diferenciar da ciência económica neoclássica, mas também de outras abordagens à economia, tais como a socioeconomia ou a 'velha' economia institucionalista. (Swedberg, 2004: 325, itálico nosso)

É curiosa esta afirmação de Swedberg, pois, se por um lado a NSE reclama - pelo menos em certo grau - uma herança polanyiana, por outro lado sentiu uma necessidade de se afastar da "velha" economia institucionalista. Ora, como é sabido, Polanyi é normalmente associado a essa mesma "escola", no seguimento de autores como Veblen, Commons, etc. (cf. Stanfield, 1986).

\subsection{Revisão da literatura}

Podemos afirmar que a posição clássica da NSE continua a ser aquela inaugurada por Granovetter (1985), que associa intimamente o conceito de (des)incrustação ao de redes sociais e, portanto, a um nível "meso" (muitas vezes "micro" até) por oposição a uma visão "macro". Em suma, esta posição defende que "o comportamento [económico] está intimamente incrustado em redes de relações interpessoais" (Granovetter, 1985: 504).

Para o autor, uma das questões centrais da teoria social tem sido a de perceber em que medida o comportamento e as instituições são afectados pelas relações sociais. Neste sentido, procura analisar no seu artigo o grau em que a acção económica está incrustada em estruturas de relações sociais, 
na sociedade industrial moderna. As habituais abordagens neoclássicas preconizam uma explicação "subsocializada" (undersocialized) - ou baseada no actor atomizado - dessa acção, enquanto os economistas reformistas que procuram reintroduzir a estrutura social na análise fazem-no de um modo "sobressocializado" (oversocialized). Ambas as explicações são paradoxalmente similares na sua negligência em relação às estruturas contínuas de relações sociais (Granovetter, 1985: 481).

Assim, uma análise frutuosa da acção humana requer que evitemos a atomização implícita nos extremos teóricos, i.e., nas concepções sub- e sobressocializadas. Isto porque

Os actores não se comportam ou decidem como átomos fora de um contexto social, nem aderem automaticamente a um guião preparado para eles pela intersecção particular das categorias sociais que acontece ocuparem. As suas tentativas de acção intencional estão antes incrustadas em sistemas de relações sociais concretas e contínuas. (Granovetter, 1985: 487, itálico nosso)

No que se refere à polémica substantivistas vs. formalistas (cf. Machado, 2009: 15-54), Granovetter diz-nos que a sua

visão diverge de ambas as escolas de pensamento. Eu defendo que o nível de incrustação do comportamento económico é menor nas sociedades não-mercantis do que aquilo que é preconizado pelos substantivistas e teóricos do desenvolvimento, e que este mudou menos com a 'modernização' do que eles acreditam; mas eu argumento também que este nível foi sempre e continua a ser mais substancial do que aquele permitido pelos formalistas e economistas. (Granovetter, 1985: 482-483)

Note-se, contudo, que Granovetter não procura abordar estes assuntos relativamente às sociedades não-mercantis. Ele procede a uma elaboração teórica do conceito de incrustação, cuja importância é ilustrada por um problema da sociedade moderna: que transacções, na moderna sociedade capitalista, são levadas a cabo no mercado e quais estão subsumidas dentro de empresas organizadas hierarquicamente (Granovetter, 1985: 493).

Mas o próprio Granovetter acaba por admitir:

Tive pouco a dizer relativamente à influência das circunstâncias históricas ou macroestruturais mais abrangentes sobre as características socioestruturais que os sistemas apresentam, pelo que não preconizo esta análise para responder a questões em larga escala no que se refere à natureza da sociedade moderna ou às fontes da mudança económica e política. (Granovetter, 1985: 506, itálico nosso) 
Não obstante, "o argumento da incrustação [...] demonstra não apenas que há lugar para os sociólogos no estudo da vida económica mas que a sua perspectiva é urgentemente necessária nesse âmbito" (Granovetter, 1985: 507).

Numa intervenção particularmente elucidativa (cf. Krippner et al., 2004), Granovetter admite que, nos seus escritos dos anos mais recentes, raramente tem utilizado o conceito de incrustação "porque se tornou quase desprovido de significado (meaningless), alargado até a um ponto em que significa quase tudo, pelo que portanto acaba por não significar nada" (Krippner et al., 2004: 113). E o texto torna-se ainda mais interessante quando Granovetter lança luz sobre a génese do seu artigo seminal. Segundo o autor, ele utiliza o conceito de incrustação no seu artigo de 1985 num sentido mais estrito e algo diferente do proposto originalmente por Polanyi. Mas,

a razão é que eu não estava a tentar adoptar (borrow) o conceito de Polanyi, ou reapropriá-lo ou reintroduzi-lo. [...] Ao olhar para os meus velhos blocos de notas constatei que usava o termo 'embeddedness' em algumas dessas notas preliminares, mesmo antes sequer de ter lido Polanyi. Usava-o do modo que o utilizei no artigo de 1985, para significar o modo como as actividades económicas e sociais estão interligadas (mixed up) com redes de relações sociais. [...] Algum tempo mais tarde acabei por ler Polanyi. Li particularmente 'The Economy as Instituted Process'. Mas apenas muito mais tarde é que li cuidadosamente $A$ grande transformação. (Krippner et al., 2004: 113)

E Granovetter continua: "Quando comecei a escrever o artigo sobre a incrustação tinha, de facto, esquecido Polanyi, e não estava a pensar nele quando escrevi esse artigo" (Krippner et al., 2004: 114). Depois de o mesmo ter começado a circular em forma de draft, o autor foi saudado por um dos leitores devido ao facto de ter recuperado o conceito de incrustação de Polanyi. Todavia, só

ao ler a carta é que pensei 'é verdade! Esqueci-me completamente que Polanyi o usava [o conceito], e de uma forma algo diferente'. Então acabei por escrever um pouco sobre Polanyi nesse artigo sobre a incrustação, mas o meu principal objectivo nessa pequena seç̧ão era distanciar-me do seu uso da incrustação. (Krippner et al., 2004: 114)

Penso que as duas citações anteriores falam por si. Não deixa de ser irónico que o artigo mais amplamente citado para reclamar uma herança 
"polanyiana" na disciplina da (nova) sociologia económica tenha afinal sido escrito sem qualquer referência ao trabalho de Polanyi por parte do seu autor.

É habitualmente entendido na NSE - e este entendimento tornou-se, de certo modo, a premissa de grande parte da investigação conduzida na disciplina - que o grande objectivo de Granovetter nesse artigo seminal era defender a análise das redes sociais como o principal ou o único fim da actividade sociológica (cf., por exemplo, Swedberg, 1997: 165). Mas Granovetter pensa que foi explícito acerca da decisão estratégica que tomou relativamente à sua investigação "de olhar para as redes sociais como um nível intermédio entre os níveis inferiores e os níveis superiores." (Krippner et al., 2004: 114). Embora reconhecendo que talvez não tenha sido suficientemente claro nesse artigo, o autor preconiza ser óbvio que "não podemos só analisar as redes sociais, temos também de analisar as instituições e a cultura e a política e todos os elementos macro e micro, entre os quais está [situado] o 'nível meso' das redes sociais” (Krippner et al., 2004: 114). E o autor acaba por concluir: "Se eu soubesse que o artigo ia ser tão influente talvez tivesse tido mais cuidado a salientar que há mais [elementos] na vida do que [apenas] a estrutura de redes sociais" (Krippner et al., 2004: 115).

Por seu turno, Barber (1995) defende que "um melhor entendimento teórico geral da incrustação será bastante útil para a análise sociológica contemporânea" (1995: 388). O conceito (cultural) central com o qual a incrustação está relacionada é o de "mercado". Aliás, a história do conceito de incrustação pode ser vista como uma longa batalha para ultrapassar aquilo a que Barber chama de "absolutização do mercado" (Barber, 1995: 388).

Para o autor, a troca mercantil é interdependente de um conjunto de variáveis sociais estruturais e culturais que constituem os modernos sistemas sociais: equidade, eficiência, universalismo, regras específicas de propriedade, etc. (Barber, 1995: 399). Assim, embora a análise de Polanyi relativamente às três formas de integração - reciprocidade, redistribuição e troca mercantil - seja bastante valiosa, ela torna-se menos útil, enganadora até, quando discute a questão dos seus diferentes "níveis" de incrustação:

Polanyi descreve o mercado como ‘desincrustado' e os outros dois tipos de troca económica como [estando] mais 'incrustados' nos outros elementos socioestruturais e culturais-estruturais da sociedade. [Mas,] como deve agora ser claro, depois do que foi dito acerca da ligação dos três tipos de troca económica com algum conjunto de elementos sociais estruturais e culturais no seio dos sistemas sociais nos quais ocorrem, a nossa proposição forte, contrária à de Polanyi, é que todas as economias estão inevitavelmente incrustadas. (Barber, 1995: 400) 
Assim,

embora o moderno sistema de mercado possa parecer mais diferenciado das outras estruturas do sistema social, de algum modo mais concretamente separado, esta visão desvia a atenção do facto básico da sua múltipla e complexa interdependência com o resto do sistema social. Designar o mercado como 'desincrustado' afasta a atenção analítica daquilo que esta interdependência é [na realidade]. (Barber, 1995: 400)

Barber lamenta mesmo que Polanyi não possuísse uma concepção explícita de um sistema social no qual a economia constitui sempre uma - e apenas uma - parte interdependente de diferentes maneiras das outras partes sociais - estruturais e culturais - essenciais de qualquer sistema social particular (Barber, 1995: 401).

Segundo Barber, o artigo de Granovetter teve como principal virtude insistir precisamente na incrustação de toda a acção económica em relações sociais não-económicas. Não obstante, lança algumas críticas a esse artigo. A principal é que a análise de Granovetter "não revela um entendimento da importância dos sistemas sociais mais vastos nos quais todas as economias estão localizadas" (Barber, 1995: 406). E o autor continua:

Granovetter diz que o comportamento económico está incrustado na 'estrutura social', e para ele a estrutura social significa aparentemente somente redes de relações interpessoais. Não há qualquer especificação das diferentes estruturas sociais e culturais que compõem o sistema social mais vasto. Para onde é que desapareceram as estruturas sociais do parentesco, estratificação, género, idade, economia, política, organizações, educação e comunicações? (ibidem: 406-407)

Em suma, a tese principal de Barber é que o desenvolvimento mais desejável do conceito de incrustação seria reconhecer que todos os tipos de economias estão incrustados em complexos sistemas sociais mais abrangentes. Por outro lado, as componentes socioestruturais, culturais-estrurais e de personalidade desses sistemas deveriam ser especificadas. Para completar, as suas inter-relações com os sistemas económicos - que não são mais do que uma parte do sistema social - devem assim ser mais bem entendidas e, então, estabilizadas ou transformadas (Barber, 1995: 407-408).

Block (cf. 2000; 2003) apresenta talvez a visão mais distinta no seio da NSE, embora acabe também por concluir que todas as economias estão incrustadas. Em primeiro lugar, há que destacar que este autor apreende o conceito no sentido que lhe foi inicialmente impregnado por Polanyi, i.e., como referindo-se a uma perspectiva "macro", a um entendimento do 
sistema económico como um todo. Todavia, as suas conclusões são diferentes das de Polanyi no que toca à desincrustação do capitalismo.

Segundo Block, existe uma tendência latente para a desincrustação no seio da moderna economia de mercado, ou seja, a economia aproxima-se bastante dessa situação empiricamente. Não obstante, a "plena" desincrustação é simplesmente impossível na medida em que isso destruiria imediatamente a sociedade. Em virtude da necessidade de intervenção do Estado e de protecção social, nomeadamente no que respeita à regulação das mercadorias fictícias, a economia, mesmo a capitalista, "está sempre incrustada". Assim, segundo o autor, a economia auto-regulada não passa de uma utopia (negra). O próprio Karl Polanyi preconiza esta impossibilidade prática de uma completa desincrustação, embora de forma ambígua. Esta ambiguidade derivaria da tensão que se estabelece entre um Polanyi influenciado por um quadro teórico marxista (até aos anos 30) e um segundo Polanyi ligado aos conceitos e posições desenvolvidas pelo autor no processo de escrita em $A$ grande transformação, que muitas vezes contrariavam as desse quadro de referência original (cf. Block, 2003). Em síntese, o capitalismo caminha para a desincrustação, aproxima-se bastante desse estado, mas, no limite, nunca poderá atingi-lo sem que isso signifique o colapso da sociedade.

Em várias situações, Polanyi parece de facto confirmar as asserções de Block, como quando afirma que "a ideia de um mercado auto-regulável implicava uma rematada utopia” (Polanyi, 2000: 18). Todavia, note-se que ele escreve isto em $A$ grande transformação, quando acredita estar a testemunhar, finalmente, o colapso da "civilização do século XIX", ou seja o fim da sociedade assente no mercado auto-regulado (cf. Polanyi, 2000: 17-18). Assim, o mercado auto-regulado havia provado a sua incapacidade prática para organizar a vida das sociedades humanas. É do falhanço empírico do sistema capitalista (que, como sabemos hoje, não ocorreu de facto...) que deriva a "utopia" (distopia), então desmentida pelos acontecimentos: não do facto de nunca ter existido um mercado auto-regulado, mas do facto de a sua existência durante um período de tempo (relativamente) pequeno ter conduzido a humanidade à maior crise da sua história. Na óptica de Polanyi, foram os acontecimentos históricos (reais) que invalidaram as supostas virtudes do mercado, marcando o início de uma "grande transformação" caracterizada pela introdução de outras experiências económicas (socialismo, fascismo e New Deal). A "utopia" do mercado auto-regulado não deriva da sua impossibilidade prática, mas sim da crença de que este poderia funcionar indefinidamente sem provocar efeitos profundamente nocivos para o Homem e para a natureza. "A civilização industrial continuará a existir 
mesmo quando a experiência utópica de um mercado auto-regulável não for mais do que uma lembrança" (Polanyi, 2000: 290).

Krippner está bem ao corrente das diferenças entre o conceito de incrustação proposto originalmente por Polanyi e aquele preconizado por Granovetter, efectuando uma recensão bastante minuciosa das duas visões (cf. Krippner e Alvarez, 2007). Apesar de reconhecer o mérito da contribuição de Granovetter, no sentido de demonstrar que todas as economias estão incrustadas, a autora critica o facto de o campo da NSE se ter desenvolvido e moldado quase exclusivamente em torno desse mesmo conceito (Krippner, 2001: 775-776).

O que se passa é que a (nova) sociologia económica, mais do que grande parte dos subcampos da sociologia, está construída sobre uma ideia-chave: o conceito de incrustação. Deste modo, Krippner argumenta que a noção de incrustação deflectiu a atenção de outros problemas teóricos importantes. Em particular, sugere que a relativa negligência do conceito de mercado na sociologia económica é o resultado da maneira como a noção de incrustação foi formulada. Paradoxalmente, a intuição básica de que os mercados estão socialmente incrustados - em si mesma extremamente útil - conduziu os sociólogos económicos a encarar o mercado como um dado adquirido. Consequentemente, a sociologia económica não conseguiu fazer muito melhor do que a economia no que toca à elaboração do conceito de mercado como um objecto teórico de pleno direito, assistindo-se a um curioso subdesenvolvimento do conceito de mercado no seio da disciplina (Krippner, 2001: 776; Krippner et al., 2004: 111-112).

Ao tentar estabelecer um meio-termo entre as visões sub- e sobressocializadas da acção, Granovetter acabou por “assentar arraiais” numa concepção, comum a ambas, que insiste na natureza separada da economia e da sociedade. Este problema manifesta-se numa curiosa simetria que existe na disciplina: os investigadores ou estudam os processos económicos em termos sociais, caso em que abandonam a esfera do mercado, ou estudam o mercado como uma entidade teórica de pleno direito, caso que em que expurgam todo o seu conteúdo social (Krippner et al., 2004: 112-113).

Assim sendo, enquanto o mercado não for completamente apropriado como um objecto social, continuará a existir uma tensão entre, por um lado, concepções não-mercantis (marketless) do social e, por outro lado, concepções da economia em que qualquer traço social é suprimido (Krippner et al., 2004: 113).

Beckert (2007) apresenta uma boa síntese da evolução do conceito de incrustação. Assim, salienta que - como já aqui foi mencionado - na sua adaptação de Polanyi, o conceito sofreu uma "grande transformação", 
perdendo-se alguns elementos da noção original ao mesmo tempo que se adicionaram outros (Beckert, 2007: 7). Beckert destaca ainda outros elementos que já abordámos: a ironia em torno do conceito, associada ao facto de Granovetter não ter em mente o trabalho de Polanyi aquando da escrita do seu artigo (Beckert, 2007: 9-10); o facto de o conceito introduzido por Granovetter estar intimamente ligado ao de redes sociais (Beckert, 2007: 8-9); e a predominância assumida por essa interpretação no seio da NSE (Beckert, 2007: 9).

Beckert critica a análise de redes e a posição assumida por Granovetter, na medida em que

esta é uma perspectiva limitada, uma vez que um foco exclusivo na estrutura das relações sociais conduz a uma negligência do conteúdo social subjacente à estrutura observada. Ao não levar em linha de conta os atributos dos actores e as regras institucionais, a análise de redes não consegue explicar como é que a estrutura social dos mercados emerge e porque é que as redes estão estruturadas de uma determinada maneira [e não de outra]. (Beckert, 2007: 9)

E mais, Beckert defende que o conceito de incrustação não constituirá a melhor maneira de abordar a economia de um ponto de vista sociológico. Neste sentido,

podemos questionar se a sociologia deve partir desta noção como o seu ponto de entrada no campo da economia. A minha posição é que a 'incrustação' caracteriza uma resposta geral a problemas específicos sem identificar esses problemas que the estão subjacentes. Ao começar pela incrustação da acção económica estamos a pôr o carro à frente dos bois. O primeiro passo deveria [antes] ser identificar os problemas que podem realmente ser resolvidos por uma abordagem focalizada na incrustação da acção económica. Eu sugiro que identifiquemos esses problemas e os tomemos como ponto de partida analítico da sociologia económica. (Beckert, 2007: 10-11)

A NSE deve então tomar como o seu ponto de partida os "três problemas de coordenação" que os actores enfrentam na troca mercantil: o problema do valor, o problema da competição e o problema da cooperação (cf. Beckert, 2007: 11-15).

De acordo com o autor, a atracção que Polanyi exerce sobre a NSE deriva do facto de a sua teoria social não implicar um "conceito linear de desenvolvimento", i.e., a incrustação não é uma característica que separa as economias pré-modernas das economias modernas. Baseada na noção de "movimento duplo", a mudança social é conceptualizada como um 
processo dinâmico de oscilação entre a incrustação, a desincrustação e a reincrustação. Portanto, todas as economias estão (de algum modo) incrustadas (Beckert, 2007: 19). Como decerto se perceberá pela análise empreendida até aqui, não podemos concordar com esta interpretação, que, como veremos um pouco mais adiante, se revela problemática para Beckert. Em síntese, passa-se exactamente o contrário do que aquilo que é preconizado pelo autor: Polanyi não podia ser mais claro ao afirmar que todas as economias até uma época bastante recente - antes da emergência da economia de mercado capitalista - estavam incrustadas na sociedade. Portanto, a desincrustação/contra-resposta defensiva/necessidade de reincrustação da economia é um "problema" bastante recente e não algo que esteve sempre presente ao longo da história. Ao não reconhecer - tal como os outros autores da NSE - que a especificidade da economia capitalista é precisamente o seu carácter desincrustado, defendendo que "todas as economia estão incrustadas”, Beckert acaba por esbarrar num problema sem solução aparente. Diz o autor:

todavia, a 'incrustação' não providencia uma perspectiva teórica capaz de nos informar acerca das características específicas da incrustação das modernas economias capitalistas. A forte ênfase nas similaridades dos sistemas económicos ao longo do tempo e do espaço, baseada na noção de incrustação, impede o desenvolvimento de instrumentos conceptuais para captar as diferenças entre as configurações económicas e, em particular, a especificidade da organização das economias capitalistas modernas. (Beckert, 2007: 19, itálico nosso)

Nestas linhas de Beckert, embora ele não se aperceba disso, está sintetizada a crítica que temos vindo a efectuar ao entendimento do conceito de incrustação por parte da NSE. Continuemos com Beckert: "isto deixa-nos com uma sociologia económica que é inespecífica em relação às mudanças estruturais que ocorrem na organização da economia com o desenvolvimento do capitalismo moderno. Afinal de contas, todas as economias estão incrustadas" (Beckert, 2007: 19, itálico nosso).

Em suma, o autor concorda com a posição dominante na NSE segundo a qual todas as economias - incluindo a capitalista - estão incrustadas. No entanto, ao contrário da maioria dos seus colegas, apercebe-se do problema - da contradição, diríamos nós - que isso coloca: como realçar o carácter absolutamente excepcional da moderna economia capitalista de mercado? Este problema acaba por não se colocar na NSE porque a disciplina não reconhece essa singularidade: a economia capitalista é "apenas” mais uma economia, que não representa nada de extraordinário 
relativamente às economias do passado. Ontologizando as características da economia capitalista, percebe-se que pareça estranho dizer que essa economia está "desincrustada" - esta sim configura-se como uma afirmação extraordinária.

Podemos concluir que o conceito de incrustação

permitiu a concentração [da NSE] nos processos de nível meso e micro da organização económica e libertou os sociólogos da tarefa de tratar o desenvolvimento socioeconómico ao nível macro. [...] Precisamos de uma perspectiva histórica se queremos compreender as formas específicas nas quais a acção económica está [des]incrustada nas [das] instituições e estruturas sociais das sociedades modernas. (Beckert, 2007: 19)

\subsection{Avaliação crítica}

Parece-nos que as visões de Randles (2003), Lie (1991) e Gemici (2008) sintetizam bem as posições predominantes na NSE, fornecendo assim um bom ponto de partida para a nossa avaliação crítica da mesma. Segundo Randles (cf. 2003: 420-421), Polanyi admite em $A$ grande transformação a desincrustação dos mercados; mas em "The Economy as Instituted Process" a desincrustação é uma mera possibilidade (teórica), pois os mercados estão de algum modo institucionalizados. Lie (cf. 1991: 219-223) diz-nos que a "tese" da incrustação, preconizando que todas as actividades e instituições económicas estão imiscuídas em relações e instituições sociais, constitui uma boa base teórica para a NSE. Todavia, Polanyi "falha" ao não incrustar o conceito de mercado. Esta tese deve então ser levada à sua conclusão lógica e os mercados devem igualmente ser incrustados, passando a ser tratados como redes sociais ou organizações constituídas por mercadores (traders). Gemici realça a mesma contradição, concluindo que "todas as economias estão incrustadas, uma vez que a vida económica é um processo instituído e organizado socialmente" (2008: 9). Entretanto, e para evitar confusões, deve-se notar que para Polanyi os dois termos não são equivalentes, ou seja, institucionalização é diferente de incrustação. ${ }^{12}$

A troca mercantil, enquanto forma de integração, traduz-se num padrão institucional constituído por um sistema de mercados formadores de preços, mas é precisamente a acção (autónoma) desse mecanismo institucional que conduz à desincrustação da economia. Polanyi define a economia como um processo instituído constituído por dois níveis: um refere-se à interacção

${ }^{12}$ Cf. Lacher (1999: 345-346) para uma distinção entre proteccionismo e reincrustação, outra das confusões mais comuns, particularmente nos trabalhos associados ao estudo da globalização. 
do homem com o ambiente natural e social que o rodeia; o outro refere-se à institucionalização desse processo. Todas as economias, independentemente da sua forma de integração dominante, partilham estas características. Assim, parece claro que Polanyi não nega, de modo algum, esta relação entre a economia humana e o sistema social. O que se passa é que no capitalismo todas as considerações, motivações e valores sociais são relegados para segundo plano em face da primazia adquirida empiricamente pela economia, que se autonomiza de todo e qualquer controlo social (consciente). De acordo com Polanyi, numa sociedade pós-capitalista, nomeadamente com a abolição do carácter mercantil fictício do trabalho, da terra e do dinheiro, a regulação social passará por uma administração democrática e participada do processo produtivo, mediante a intervenção de instituições como o Estado, os sindicatos, as cooperativas, as fábricas, os distritos, as escolas, as igrejas, etc. (cf. Polanyi, 2000: 290-292).

Deste modo, diríamos que a economia não pode ser "social" se a sociedade - as pessoas que a compõem e as instituições que criam - não são capazes de a dirigir mas, pelo contrário, é a economia que as controla e define o seu destino. É claro que existe sempre "uma conexão da economia [...] com algum tipo de elementos sociais estruturais e culturais [no seio] do sistema social no qual ela ocorre" (Barber, 1995: 400), mas no capitalismo essa ligação dá-se não sob a forma de uma interdependência, mas sim de um primado da economia sobre a totalidade do sistema social. É por isso mesmo que Polanyi fala de uma desincrustação dessa economia.

Provocando Granovetter, diríamos que se a acção humana "está incrustada em sistemas de relações sociais contínuas e concretas" (1985: 487), esses sistemas sociais são por sua vez enquadrados, e largamente determinados, por uma economia desincrustada. Estão inseridos num quadro de referência mais vasto caracterizado por uma economia que escapa ao controlo dos homens, que lhes é estranha e que os subjuga. Não é a economia que está enquadrada no sistema social, mas o sistema social que é enquadrado pela economia.

Podemos concluir que se Polanyi pretende estudar o lugar ocupado pela economia nas diferentes sociedades, a NSE, por seu turno, afirma que o lugar e o papel desempenhado pela economia é, no essencial, sempre o mesmo. Tal como os formalistas no campo da antropologia económica, acaba por incorrer na denominada "falácia economicista", isto é, na identificação automática e acrítica da economia com a sua forma de mercado (cf. Polanyi, 1968a). 


\section{Esboço de conclusão}

A desincrustação da economia - a sua desvinculação da sociedade - correspondeu à ascensão histórica de um sistema automático de mercados formadores de preços. Até então, em todas as sociedades do passado a economia esteve sempre incrustada, submersa no sistema social (não está aqui em causa a desejabilidade, os méritos ou defeitos dessas sociedades). Então, o carácter "incrustado" ou "desincrustado" de uma economia, segundo Polanyi, depende intimamente da presença (ou ausência) de um sistema de mercados formadores de preços, i.e., de ser ou não uma economia de mercado. No quadro da sociedade capitalista, a economia ganha uma vida própria, independente da vontade dos homens, e julgo que é fundamentalmente a isto que corresponde a essência da "desincrustação". Neste sentido, facilmente se percebe que, pelo menos de acordo com o sentido que Polanyi atribui ao conceito, nunca as economias modernas poderão ser classificadas como estando incrustadas na sociedade, pois a "reincrustação" da economia exige a superação da forma de que se reveste actualmente.

A NSE, ao não reconhecer este carácter singular da economia de mercado, a absoluta excepcionalidade do capitalismo na história das sociedades humanas, afasta-se irremediavelmente do sentido original imposto por Polanyi ao conceito de (dis)embeddedness. Como nota Randles, parece haver na NSE a tendência para

uma apropriação secundária de Polanyi largamente fragmentada (e fragmentária). Hoje em dia o nome de Polanyi é frequentemente usado como uma 'etiqueta' que está na moda ou como um ponto de partida conveniente para uma discussão que depois se assemelha bastante pouco, e oferece uma análise reduzida - elogiosa, crítica ou qualquer outra - da 'totalidade' dos escritos de Polanyi. Talvez seja isto que preocupa Polanyi-Levitt [filha de Karl Polanyi] quando se refere ao potencial abuso do legado de Polanyi. (Randles, 2003: 418)

Polanyi, para além de analisar, pretendeu acima de tudo criticar a economia capitalista e denunciar os seus efeitos profundamente nocivos para o Homem e para a natureza. Uma perspectiva que ignora esta dimensão crítica - apropriando selectivamente um conceito e esquecendo (desconhecendo?) todo o restante quadro teórico e analítico do autor, bem como a sua relação com esse conceito - não pode nunca reclamar a sua herança, pelo que será um erro afirmar-se que, hoje em dia, no âmbito da NSE, "somos todos Polanyianos” (Beckert, 2007: 7), um equívoco que em nada honra a sua memória. 


\section{Referências bibliográficas}

Barber, Bernard (1995), "All Economies Are 'Embedded': The Career of a Concept and Beyond”, Social Research, 62(2), 387-413.

Beckert, Jens (2003), "Economic Sociology and Embeddedness: How Shall We Conceptualize Economic Action?”, Journal of Economic Issues, 37(3), 769-787.

Beckert, Jens (2007), "The Great Transformation of Embeddedness - Karl Polanyi and the New Economic Sociology", MPIfG Discussion Paper No. 1/07, consultado em 18/04/2009, http://www.mpifg.de/pu/mpifg_dp/dp07-1.pdf.

Block, Fred (2000), "Introduction to The Great Transformation", consultado em 25/11/2010, http://www2.dse.unibo.it/ardeni/papers_development/FredBlock_ Introduction-to-Polanyi.pdf.

Block, Fred (2003), "Karl Polanyi and the Writing of The Great Transformation", Theory and Society, 32(3), 275-306.

Cumberpatch, Chris G. (2001), "Some Observations on the Concept of 'Embedded' and 'Disembedded' Economies in Archaeological Discourse”, Assemblage, 6, consultado em 18/04/2009, http://www.assemblage.group.shef.ac.uk/issue6/Cumberpatch_ Econ_web.html.

Gemici, Kurtulus (2008), "Karl Polanyi and the Antinomies of Embeddedness", Socio-Economic Review, 6, 5-33.

Ghezzi, Simone; Minzione, Enzo (2007), "Embeddedness, Path Dependency and Social Institutions: An Economic Sociology Approach", Current Sociology, 55(1), 11-23.

Graça, João Carlos (2005), "Afinal, o que é mesmo a Nova Sociologia Económica?", Revista Crítica de Ciências Sociais, 73, 111-129.

Granovetter, Mark (1985), "Economic Action and Social Structure: The Problem of Embeddedness", The American Journal of Sociology, 91(3), 481-510.

Hess, Martin (2004), "'Spatial' Relationships? Towards a Reconceptualization of Embeddedness", Progress in Human Geography, 28(2), 165-186.

Knowles, Rob (2000), "Political Economy From Below: Communitarian Anarchism as a Neglected Discourse in the Histories of Economic Thought", History of Economics Review, 31, 30-47.

Knowles, Rob; Owen, John R. (2008), "Karl Polanyi for Historians: An Alternative Economic Narrative”, The European Legacy, 13(2), 175-191.

Krippner, Greta (2001), "The Elusive Market. Embeddedness and the Paradigm of Economic Sociology", Theory and Society, 30, 775-810.

Krippner, Greta et al. (2004), "Polanyi Symposium: A Conversation on Embeddedness", Socio-Economic Review, 2(1), 109-135.

Krippner, Greta; Alvarez, Anthony (2007), "Embeddedness and the Intellectual Projects of Economic Sociology", Annual Review of Sociology, 33, 219-240.

Lacher, Hannes (1999), "Embedded Liberalism, Disembedded Markets: Reconceptualising the Pax Americana", New Political Economy, 4(3), 343-360. 
Lie, John (1991), “Embedding Polanyi’s Market Society”, Sociological Perspectives, $34(2), 219-235$.

Machado, Nuno (2009), Sociedade vs. mercado - notas sobre o pensamento económico de Karl Polanyi. Tese de Mestrado em Sociologia Económica e das Organizações. Lisboa: ISEG.

Polanyi, Karl (1957), “Aristotle Discovers the Economy”, in Karl Polanyi; Conrad Arensberg; Harry Pearson (orgs.), Trade and Market in the Early Empires. Chicago: Henry Regnery, 64-94.

Polanyi, Karl (1966), Dahomey and the Slave Trade: An Analysis of an Archaic Economy. Seattle and London: University of Washington Press.

Polanyi, Karl (1968a), "The Economy as Instituted Process”, in George Dalton (org.), Primitive, Archaic and Modern Economies: Essays of Karl Polanyi. Boston: Beacon Press, 139-174.

Polanyi, Karl (1968b), "Our Obsolete Market Mentality”, in George Dalton (org.), Primitive, Archaic and Modern Economies: Essays of Karl Polanyi. Boston: Beacon Press, 59-77.

Polanyi, Karl (1977a), “The Economistic Fallacy”, in Karl Polanyi; Harry Pearson (orgs.), The Livelihood of Man. New York: Academic Press, 5-17.

Polanyi, Karl (1977b), “The Economy Embedded in Society”, in Karl Polanyi; Harry Pearson (orgs.), The Livelihood of Man. New York: Academic Press, 47-56.

Polanyi, Karl (1977c), "The Two Meanings of Economic”, in Karl Polanyi; Harry Pearson (orgs.), The Livelibood of Man. New York: Academic Press, 19-34.

Polanyi, Karl (2000), A grande transformação: as origens da nossa época. Rio de Janeiro: Editora Campus.

Polanyi, Karl; Arensberg, Conrad; Pearson, Harry (1968), "The Place of Economies in Societies”, in George Dalton (org.), Primitive, Archaic and Modern Economies: Essays of Karl Polanyi. Boston: Beacon Press, 116-138.

Polanyi-Levitt, Kari (2003), "The English Experience in the Life and Work of Karl Polanyi”. Comunicação apresentada no congresso "Polanyian Perspectives on Instituted Economic Processes, Development and Transformation”, ESRC, Center for Research on Innovation and Competition, University of Manchester, 23-25 de Outubro.

Randles, Sally (2003), "Issues for a Neo-Polanyian Research Agenda in Economic Sociology”, International Review of Sociology, 13(2), 409-434.

Stanfield, James R. (1986), The Economic Thought of Karl Polanyi. London: Macmillan. Swedberg, Richard (1997), "New Economic Sociology: What Has Been Accomplished, What Is Ahead?", Acta Sociologica, 40, 161-182.

Swedberg, Richard (2004), "What Has Been Accomplished in New Ecnomic Sociology and Where is it Heading?”, Archives Européennes de Sociologie, 45(3), 317-330.

Swedberg, Richard (2006), "The Toolkit of Economic Sociology", SOCIUS Working Papers, No. 4/2006. 